\title{
Financial management and phenomenology: The role of dialogue, accountability and context in investment decisions
}

\begin{tabular}{|c|c|}
\hline \multicolumn{2}{|c|}{$\begin{array}{l}\text { Authors: } \\
\text { Mark Rathbone }{ }^{1} \text { (1) } \\
\text { Surika van Rooyen }{ }^{2} \text { (]) }\end{array}$} \\
\hline \multicolumn{2}{|c|}{$\begin{array}{l}\text { Affiliations: } \\
{ }^{1} \text { Department of Business } \\
\text { Management, Faculty of } \\
\text { Economic and Management } \\
\text { Sciences, North-West } \\
\text { University, Potchefstroom, } \\
\text { South Africa }\end{array}$} \\
\hline \multicolumn{2}{|c|}{$\begin{array}{l}{ }^{2} \text { Department of Accounting } \\
\text { Sciences, Faculty of Economic } \\
\text { and management sciences, } \\
\text { North-West University, } \\
\text { Potchefstroom, South Africa }\end{array}$} \\
\hline \multicolumn{2}{|c|}{$\begin{array}{l}\text { Corresponding author: } \\
\text { Mark Rathbone, } \\
\text { mark.rathbone@nwu.ac.za }\end{array}$} \\
\hline \multicolumn{2}{|c|}{$\begin{array}{l}\text { Received: } 11 \text { June } 2020 \\
\text { Accepted: } 04 \text { Dec. } 2020 \\
\text { Published: } 23 \text { Mar. } 2021\end{array}$} \\
\hline \multicolumn{2}{|c|}{$\begin{array}{l}\text { How to cite this article: } \\
\text { Rathbone M, Van Rooyen S. } \\
\text { Financial management and } \\
\text { phenomenology: The role of } \\
\text { dialogue, accountability and } \\
\text { context in investment } \\
\text { decisions. J transdiscip/ res } \\
\text { S Afr. 2021;17(1), a894. } \\
\text { https://doi.org/10.4102/ } \\
\text { td.v17i1.894 }\end{array}$} \\
\hline \multicolumn{2}{|l|}{$\begin{array}{l}\text { Copyright: } \\
\text { ( 2021. The Au } \\
\text { Licensee: AOSIS } \\
\text { is licensed unde } \\
\text { Creative Comm } \\
\text { Attribution Licel }\end{array}$} \\
\hline \multicolumn{2}{|l|}{ Read online: } \\
\hline 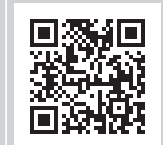 & $\begin{array}{l}\text { Scan this QR } \\
\text { code with your } \\
\text { smart phone or } \\
\text { mobile device } \\
\text { to read online. }\end{array}$ \\
\hline
\end{tabular}

In this article, it will be argued that subjective assumptions play a prominent part in the way valuations are conducted and investment decisions are made by financial managers (FMs) from the perspective of agency theory. The problem is that there is a general absence of rules of compliance for financial management. Quantitative calculations are based on theories, models and accepted practices that guide FMs in their decision-making process. The selection criteria that inform these theories, models and practices rely on qualitative assumptions, which are informed by the presuppositions of the FM. The problem is that this understanding framework has traditionally not been assessed because of the assumption that the theories, models and practices are value neutral. Value neutrality generally implies that calculations, processes and projections are based on factual information and rational procedures that are objective. The scrutiny of the assumptions involved in financial management assumes that the individual has philosophical sensitivity. However, this is not traditionally part of the expected competencies of finance professionals. Philosophical competency means that the FM is capable of evaluating decision-making processes in order not to fall into the trap of circular logic or solipsism as highlighted by Gadamer. Maurice Merleau-Ponty identified that the limitations of such an understanding of reality result in a failure of responsibility and accountability. From the philosophy of Merleau-Ponty, there are three principles for philosophical analysis, namely, dialogue, accountability and context. These principles are applied to the purchase of Gourmet Burger Kitchen by Famous Brands in 2016.

Keywords: valuations; phenomenology; Famous Brands; financial management; investment decisions.

\section{Introduction}

This research article focusses on philosophical analysis of the practice of financial management and the role that qualitative assumptions play in decision-making processes with special reference to valuations. Qualitative assumptions incorporate the presuppositions involved in the practice of financial management, such as experience, intuition and selection of appropriate models. These qualitative assumptions are in many cases unavoidable because of the uncertainty surrounding future predictions, such as cash flows, profit, growth and discount rates. The contribution of this theoretical evaluation is the introduction of philosophy as a possible resource for the financial manager (FM) to develop a critical and embedded ethical framework. In this regard, assumptions are not viewed as a problem to be avoided but they are part of the interpretative process as will be highlighted by phenomenology.

In order to avoid ethical problems associated with egoism and solipsism in expressions of greed and narcissism that could jeopardise the decision-making processes of FMs, the field of phenomenology will be explored. The work of Maurice Merleau-Ponty will be explored in light of his more integrative view of perception as both cognitive and physical. This integrative perspective is crucial for decision-making that is more socio-ethically aware of evaluating the impact of decisions on the society. In this article, three principles that are embedded in interpretation that could form the basis of responsible decision-making are identified, namely, dialogue, accountability and context. These principles reveal the limits of business theories like agency theory, and introduce a more holistic and ethical perspective that goes beyond business decision-making that focuses on value creation for shareholders (as principals) and their agents. ${ }^{1}$ In general, the agency theory attempts to explain the relationship between the owners of a company and the agents that they employ to manage the company on their behalf. ${ }^{2}$ 
The relationship between a principal and an agent may become problematic because shareholder's interest may not always be aligned with the interests of agents, for example, sustainability of business versus shareholder's self-interest. In this regard, the principles that will be highlighted in this article can offer a more encompassing perspective to address these kinds of problems.

In the first part of the article, the investment decision-making role and function of FMs are discussed with a focus on valuations. The study highlighted that subjective assumptions play a prominent part in the way valuations are conducted and investment decisions are made. In the second part, the role of subjective assumptions will be explored philosophically. The work of Merleau-Ponty on embodied perception is discussed as a possible view that moves beyond the ethical problems associated with subjectivity and more encompassing perspectives on perception. Next, three principles for an embedded ethical framework for FMs will be identified and discussed based on the work of MerleauPonty, namely, dialogue, accountability and contextual awareness. Finally, the purchase of Gourmet Burger Kitchen (GBK) by Famous Brands in 2016 was used as the case study to highlight the dangers of subjectivity and how an embedded ethical framework could have avoided subsequent problems with this purchase.

\section{Financial management, investment decisions and qualitative assumptions}

The role of the FM in organisations from the perspective of agency theory is to make decisions that will facilitate the organisation in achieving its goals of satisfying shareholders' interest as mediated by their agents. Financial managers make crucial decisions that have an influence on the future performance, as well as on the long-term sustainability and value of the organisation. These decisions involve seeking finance (financing decision) and deciding on the appropriate opportunities for these funds to be invested (investment decisions) in order to increase the value of the organisation. It is expected that the FM would opt to make the best decisions for the best possible outcome $^{3}$ and maximise the value of the organisation's shares. ${ }^{4}$ The problem is that the decisions of FMs may be influenced by the short-term interests of principals as communicated by their agents rather than the sustainability of the business. This situation is perpetuated by the fact that unlike Financial Reporting where there are rules or standards, issued by International Accounting bodies, that guide the accountant in reporting financial results, the FM does not have a set of fixed rules or standards to abide by. Instead of fixed rules and standards, the discipline of financial management uses various models and techniques for making investment and financing decisions. In theory, these models are considered to be rigorous models that can be used for the decision-making process. ${ }^{5,6}$
The net present value (NPV) model and the discounted cash flow (DCF) model are examples of these models, which are commonly used in investment decisions, for example, in deciding whether to invest in another company or a project. These models are but two of the models used in making investment decisions. In determining the value of a company, the three main approaches that are most commonly used in South Africa include the income approach, market approach and asset value approach. The income approach or DCF approach uses the estimated future cash flows expected to be generated by the business in the future. The market approach or market multiple approach determines the value of a business by comparing the company with other similar listed companies in the industry and transactions in its industry. Previous transactions in the ordinary shares of the company are also evaluated using an appropriate valuation multiple. The net assets approach determines the value of a company by determining the difference between the market value equivalents of the assets and the market value of the liabilities. ${ }^{7}$

In a research report published by PricewaterhouseCoopers $(\mathrm{PwC})$ on valuation methodologies used in South Africa, West Africa and East Africa, it was found that the DCF approach is the most commonly used valuation method. The findings of this report are consistent with those of the previous years. The reason cited for the DCF approach being preferred above the market approach is that the number of comparable companies in the South African market is limited..$^{7}$ It is for this reason that this study focusses on the DCF model as the preferred method of valuation.

Both the DCF and NPV models involve estimating the future cash flows of a project or company and discounting these cash flows at a required rate of return, which is usually the cost of capital of the organisation, in order to derive the present value of the future cash flows. ${ }^{8}$ These models are reliable and are helpful in making investment decisions. ${ }^{5}$ Graham and Harvey ${ }^{9}$ showed that most companies in fact use the NPV model to evaluate investment opportunities. However, those who use this model do not always 'rigorously adhere to it'. ${ }^{5}$ The reliability of the NPV and DCF methods depend on the inputs used by the Hornung ${ }^{10}$ agreed that the reliability of the outcome of the decision based on the NPV calculation is dependent on the reliability of the projection of the future cash flows that will be generated by the project, as well as on the determination of a suitable discount rate. The assumption is that the data used in these models are objectively sourced, and that the outcome is not informed by the assumptions of the FM.

A number of researchers ${ }^{11,12,13,14,15}$ have shown that there is a direct link between maximising NPV and maximising shareholder's wealth. In order for this to hold true, the cost of capital rate that is used as the discount rate has to be theoretically correct, calculated using a market model, such as the capital asset pricing model, arbitrage theory and 
multifactor models. These calculations must be appropriately, and often subjectively, adjusted for the relevant risk. The rate is derived using the required return on a similar traded asset with a similar risk profile than the project that is being evaluated. ${ }^{6}$ Decision makers use the NPV model to discount cash flows, ${ }^{9}$ but the discount rate used is often a subjective hurdle rate that is used as a cutoff for acceptability and the discount rate is not appropriately adjusted for risk. 5,6,16,17 This is usually the case in smaller firms where the hurdle rate is often prescribed by the investors and a single hurdle rate is used for all projects in a company even if they have different risk characteristics. ${ }^{9}$ Empirical evidence shows that subjective discount rates are used by decision makers instead of a rational cost of capital calculated using a market model, and 'as a result, they employ a criterion generated in the realm of unbounded rationality but give it a distinctive boundedrationality flavor' ${ }^{6}$

Another uncertainty involved in applying financial decision-making models is that the FM has to choose the most appropriate model for the decision at hand, ${ }^{18}$ for example, choosing between the DCF model and market approach when performing valuation. Luft and Shields ${ }^{19}$ pointed out that research and practice have shown that although models and quantitative techniques are available to assist managers in their decision-making, many managers opt for subjective decisions rather than relying on the quantitative techniques available. The point is that qualitative, often subjective, assumptions of the FM are part of the decision-making process and can, therefore, not be viewed as value neutral.

Daily et al. ${ }^{20}$ stated that management is likely to act in their own interest. The reward for the shareholders of an organisation is a combination of dividends and capital growth on their share investment. Management will, however, attempt to increase their performance in order to earn a higher salary or bonus or even to find another job with higher compensation by showing their managerial skills. As a result, managers could be focused on short-term profits instead of long-term goals. Adler ${ }^{21}$ warned that investment decisions are often 'viewed through an exceedingly narrow decision-making lens' that it could have a short-term focus, and that possible incentives offered could result in possible partisan thinking by the FM. Management and shareholders will also probably have different views on risks and based on these different views make different decisions. Decision-making models rely on inputs that are often subjective or complicated estimations, and these estimations could be influenced by managers being either too conservative or too optimistic. ${ }^{3}$ 'The behavior of the NPV-minded decision makers are often biased, self-inconsistent, frame-dependent, and lead to nonsensical and whimsical consequences'. ${ }^{5}$

\section{Luft and Shields ${ }^{19}$ stated that:}

[S]ubjective phenomena play an important role in management accounting because subjective decision-making is widely prevalent in organizations, in spite of the array of sophisticated quantitative techniques available to support managerial decisions. (p. 2)

Given the subjective nature of the decision-making process that the FM is often faced with, it seems important that the FM should be equipped with not only technical skills but also philosophical competency that is not currently part of the curriculum of FM courses. An important mechanism that is in place is the code of ethics of professional accounting bodies, such as the Code of Professional Conduct of the South African Institute of Chartered Accountants (SAICA). Unfortunately, the problem remains that partisan influences can be technically justified and circumvented because a Code of Ethics is limited by the fact that it assumes individual's responsibility to the FM to comply. Although the General Accepted Accounting Principles (GAAPs) and International Financial Reporting Standards (IFRS) provide guidelines for ethical and professional conduct for reporting financial results the need for philosophical competency goes much further and highlights the importance of critical and self-reflective skills for decision-making process. This is crucial when dealing with complex and sometimes conflicting principal or agent relations that may influence the decision of the FM.

Although philosophical skills and ethics have been given attention in accounting curricula, accounting education and training have been seen as mostly concerned with technical issues. The scope and depth of material on ethical issues and other soft skills are limited as evidenced by the lack of coverage in Financial Management and Management Accounting textbooks ${ }^{22}$ which has not improved much recently. In a study in the United Kingdom, it was found that lecturers in Management Accounting mostly addressed ethics in an implicit manner without equipping students with formal theoretical tools for solving ethical problems. Management accounting lecturers responded that they believed the theoretical and practical knowledge of management accounting was more important than interest in business ethics or even knowledge of moral philosophy. ${ }^{22}$

The models highlighted in this section can only guide decision-making in terms of a better understanding of the problem and assisting in making informed decisions. They do not guarantee accurate results and require effort, creativity, experience, knowledge and critical thinking on the part of the FM. ${ }^{3}$ Financial models for decision-making rely on the presuppositions of the FM and may, therefore, consist of subjective assumptions, subjective processes in the selection of methods and/or partial forecasting and estimations. ${ }^{3}$ Even where there are quantitative techniques available for decision-making, most of these techniques still require subjective inputs and judgement. ${ }^{18}$ These subjective aspects are generally seen as an important part of the methods of the FM. The experience and discernment of the FM are underpinned by the quantitative techniques. 
Consequently, the myth that the process of decision-making is objective and value-neutral is inaccurate. The problem is that because qualitative assumptions play a role in decisionmaking process the philosophical tools are crucial for one to not fall into the trap of relativism and solipsism as reflected in the danger of short-term profiteering. It is at this point that philosophy and specifically phenomenology that attempts to move beyond subjectivism by developing a scientific study of perception and the presuppositions involved in interpretation and decision-making can contribute to the task of FMs.

\section{Qualitative assumptions, subjectivity and phenomenology}

The field of study in philosophy that deals with perceptions, subjectivity and qualitative assumptions in decision-making is phenomenology - a philosophical field of study that highlights that perception is the main source of knowledge of reality. The implication is that understanding is from a particular subjective point of view and based on presuppositions. The founding father of this field is Husser ${ }^{23}$ who attempted to develop phenomenology as a science in order to address the limitations of subjectivism in the interpretation process. The notion of phenomenology can be traced back to $\mathrm{Kant}^{24}$ who made a distinction between noumenon and phenomenon. The former refers to an object or event that exists independent from the perceiving subject that is accessible through our senses as argued by empiricists. The latter is anything that can be observed by the senses as an image-object. Kant ${ }^{24}$ understood noumenon as 'things-in-themselves' that are not directly known. What is known to the perceiving subject are phenomena or mental images that are cognitively constructed. The rational capability of the subject is used to grasp the form and order amongst phenomena. This reflects the cognitive ability of the mind in constructing categories to access the structure of reality. In other words, phenomena provide the individual the possibility to understand reality although 'things-in-themselves' are not accessible. The access is always inferred through rational categories - transcendental analytic. Transcendental refers to the possibility to move beyond immanent or meaning that is bound to particular circumstances. This development made by Kant was an attempt to move beyond the impasse between empiricism and rationalism.

Empiricism associated with Hume was critical of the presuppositions that influenced cognition and based truth on the ability of the senses to acquire sense data as the basis for decision-making. Contrarily, rationalists and idealists like Kant were equally sceptical of the ability of the mind to order and understand sense data. Therefore, rationalism assumes that logic is the basis of truth as a means to order sense data and the perceived structure of reality. Kant ${ }^{24}$ attempted to bridge this tension between empiricism and rationalism through his transcendental idealism. Transcendental idealism emphasises that the human self creates knowledge from sense impressions and universal concepts or categories. The problem with Kant's philosophy is that the noumenon or phenomenon dualism remains in an incompatible tension.

The work of Kant, ${ }^{24}$ specifically the method of perception of reality, provides an important perspective for FM and the use of qualitative assumptions. Qualitative assumptions such as experience, intuition and discernment are all part of the presuppositions used by FM when deciding what models or theories must be used to calculate a valuation of a business. The phenomenon of a valuation is a construction built from these presuppositions of the individual preparing a valuation. Therefore, the subjectivity of these presuppositions is not a problem to overcome. Phenomenology can assist FM to analyse the complex nature of how perception functions in decision-making. Awareness of the important role of qualitative assumptions highlights that it is crucial to reflect and evaluate the presuppositions that inform our perception of reality that can be traced back to Husserl ${ }^{23}$ as discussed above.

Husser ${ }^{23}$ expanded on the work of Brentano on intentionality by arguing that distinction must be made between phenomena and the act of consciousness. Phenomenology developed as a study of the structure of consciousness. This study requires that all assumptions about the existence of the physical world must be bracketed to acquire the knowledge of essences. He referred to this process as epoche. To arrive at the essence of things the obscurities and variances of reality that may cause distortions must be excluded from the reflective process. Following Brentano, Husserl agreed that all mental phenomena are directed at an object. Meaning is, therefore, not embedded in the object but rather develops as an intentional act based on an intentional object. The intentional object is the content of the mental phenomenon. It is what the mental phenomenon is all about. For example, any desire has a corresponding thing that is envisioned or the intentional desired object.

The problem associated with Husserl ${ }^{23}$ and his brand of transcendental idealism is that the question of life, reality and meaning was not addressed. This gap was addressed by Husserl's student Heidegger ${ }^{25}$ in his work Being and Time (first published in 1927) that was influenced by existentialism. The point of interpretation for Heidegger was that it is part of life that must be bestowed with meaning within the reality (ontology) of a particular time and space. Heidegger's refinement of phenomenology in terms of the individual's existential presence in the world is a helpful delineation for FM because it focusses on meaning creation as a personal experience in which history is important. The experience of meaning creation is directly linked to the knowledge acquired over time of events and other valuations, which will have a direct impact on current and future valuations that inform the qualitative assumptions of the individual. The ontological sensitivity introduced by Heidegger is a crucial aspect for FMs to consider, specifically 
in a situation where no prior experience exists or conflicting positions have to be resolved.

Later, Gadamer ${ }^{26}$ accentuated the historical aspect of Heidegger's phenomenology and argued that historical consciousness was not fixed or exists independently of our being. In Truth and Method, ${ }^{26}$ he developed phenomenological hermeneutics that was underpinned by the assumption that consciousness was embedded in the historical flow (or, horizon), and that understanding was a conscious fusion of horizons. Therefore, our presuppositions are the necessary ingredients for understanding. The assumption that value neutrality and objectivity are the basis of truth is misleading. Truth is part of a hermeneutical circle that is the basis of our understanding of reality. Phenomenological hermeneutics is premised on the notion that understanding a text, art, perceptions, and so on requires knowledge of the process of the fusion of horizons. It is not a normative process but rather descriptive. The illusions of truth as noumena or 'things-inthemselves', something Kant attempted to attain, were simply an illusion. Understanding takes place within the hermeneutical circle, beyond which we cannot exist. From this, it is clear that qualitative assumptions in valuations are implicated by the work of Gadamer, ${ }^{26}$ specifically in relations to the theories and models used in valuations. Although the calculations that follow from these models may create the perception of value neutrality they are directly linked to subjective presuppositions, as Gamader pointed out.

The problem of the hermeneutical circle is evident from the fact that it may result in solipsism (exclusive and self-centred) or self-referential truth that may negatively impede on others as if interpretation occurs in a sanitised world away from the realities of life. In other words, there is a possible ethical dilemma embedded in understanding. This problem, amongst others, was explored by Maurice Merleau-Ponty ${ }^{27}$ whose work may assist FMs with a philosophical understanding of their practices that is in the world and connected to other human beings and the environment. ${ }^{28}$ Consequently, this implies that conscious processes of meaning creation is collective rather than individual. In the Discussion section, the principles for philosophical analysis from the perspective of Merleau-Ponty will be explored.

Merleau-Ponty $27,29,30$ noted that the perceiving subject is not isolated from the world. Perception rather takes place in the world, and as the subject perceives the world, the subject is also perceived by others. This assumes that perception is embodied. This means that perception is interactive and our physical presence influences the world we live in and how we perceive reality. We perceive reality with others who have an influence in the way we understand life and who we are. This assumes firstly that engagement is a function of understanding, and further that we can be held accountable for our actions because of the direct impact it has on others in a particular context. Meaning creation is a collective activity and at the same time the whole has an impact on the parts of the interpretative system. Therefore, two important principles include dialogue or communication as a function of interpretation and being held accountable for the impact we have on each other. All of this happens in the physical world, in time and space, represented by a particular context.

Merleau-Ponty ${ }^{27}$ highlighted the fact that perception is not an individual activity and cannot be studied in isolation from other people. The communal nature of perception and the fact that physical attributes influence this process are instructive. He also highlighted the underlying ethical aspect of interpretation in which accountability is personal because there is an interface between the subject, others and the world. The face of the other is important and not an abstract unidentified person or persons. Accountability is based on relationship and recognition that we understand in dialogue with other people. The act of perception, therefore, takes place with a pervasive sense of personal responsibility that goes beyond self-interest. It rather incorporates awareness of the potential damage that our perceptions, cognition and actions may potentially have on other people and the world. The implication is that avoidance of responsibility on the basis of objectivity and value-neutral assumptions can no longer be used as an excuse for decisions that harmed others. Any decision must be taken with the realisation that we will be held accountable. This is an important shift in phenomenology that provides important principles for science.

Merleau-Ponty ${ }^{29}$ highlighted that science and ethics cannot exist in separate realms as if good science that follows the positivistic procedure is beyond accountability. Rather the opposite is true. Good science is good ethics from the perspective of embodied phenomenology and vice versa. It is, therefore, clear that phenomenology as a field of study can provide the accounting profession and specifically financial management with valuable principles. The word principle is used because the problem with methodologies is that they imply the possibility of a detached practice. This is precisely the problem. Financial manager decision-making from the perspective of embodied perception cannot take place without the engagement of the subject and all the presuppositions involved in the process. The implication is that decision-making based on business theories, such as agency theory, that are guided by the agendas of shareholders is challenged by the principles embedded in Merleau-Ponty's phenomenology. It is also highlighted that businesses decision-making takes place within the society, and that the impact of these decision should be evaluated in terms of the impact they might have on people and the environment. These principles also differ from stakeholder theory because they are underpinned by a holistic perspective that goes beyond the engagement of individual stakeholders that may result in the silencing or prioritising of some stakeholders.

From the above discussion, the principles that are highlighted in the work of Merleau-Ponty ${ }^{30}$ are the following: dialogue (communal engagement), accountability (accounting for the 
impact of and individuals meaning creation) and context (in the world - time and space). It is important to note that although three different principles are discussed, these principles are all inter-related and overlap. The implication is that they do not function in isolation and must not be viewed as separate concepts. The principles are dynamic and embedded in the phenomenological process of understanding. The principles can also be refined further and developed in much more complexity. These principles are deeply embedded in often overlooked aspects of classical economics associated with Adam Smith, and therefore, of critical importance for economics and the accounting profession. . $8,31,32^{2}$ These three principles will be discussed in the next section with specific reference to the case of Famous Brands and their purchase of GBK.

\section{Principles for philosophical analysis: The case of Gourmet Burger Kitchen}

As mentioned earlier, investment decisions in many cases involve the ability to make future projections that are based on existing financial information and estimates. These estimates are based on historical information and expectations. In order to determine the present value of a given investment, the required inputs are the expected future cash flows and the required rate of return. Both of these inputs are, however, uncertain, subjective and could potentially have an influence on the decision, which, in turn, may have a negative impact on various stakeholders. It is, therefore, crucial that the presuppositions of the FM are highlighted and the impact on stakeholders is determined. The three principles identified earlier, namely, dialogue, accountability, and context, are, therefore, crucial in the practice of determining value through DCFs. This could be a departure of the current financial management practice in which calculations and decision-making might happen in isolation and with limited engagement because it is not necessarily seen as the responsibility of the manager. The case study of GBK highlighted how the incorporation of dialogue, accountability and contextual awareness might improve valuation decisions.

\section{Case study: Gourmet Burger Kitchen}

The case of Famous Brands could be used as an example to illustrate the above-mentioned principles. Famous Brands Limited (FB) is a holding company listed in South Africa on the Johannesburg Stock Exchange Limited (JSE) and is Africa's largest branded food service franchisor. Gourmet Burger Kitchen was launched in 2001 in Battersea, South London by three New Zealanders and supported by the father of fusion, Peter Gordon. Gourmet Burger Kitchen has been viewed as a renowned leader in the premium burger category (FB website). In 2016, FB bought $100 \%$ of the equity of GBK for $£ 120$ million (R2.3b) from Yellowwoods, an investment firm controlled by the South African Enthoven family (Yellowwoods, who owns Nando's, Spier and Hollard Insurance Company Ltd, bought GBK for $£ 30 \mathrm{~m}$ in 2010). At the time of the purchase, it was estimated that FB saved approximately $£ 36 \mathrm{~m}$. Kevin Hedderwick, an executive at FB, commented that the saving was because of the devaluation of the Great Britain Pound (GBP) after the European Union referendum in June 2016 and stated that Brexit was beneficial to the company. ${ }^{33}$

The value of this investment, however, subsequently, has been reduced by more than half. This was because of lower consumer confidence, online food deliveries and competition in the industry. The JSE Sens announcement as released on 16 August 2018 revealed that GBK operation underperformed the board and management's expectations. The contribution of GBK to group profitability has taken longer than initially anticipated hampered by the adverse trading environment. This was followed by more bad news on the JSE Sens announcement of 15 October 2018, stating that GBK has recorded an operating loss of $£ 2.6 \mathrm{~m}$. In light of the continued adverse trading conditions and sustained underperformance of GBK, an impairment of R874m pre-tax (R760m post tax) was made. The basic loss per share for the group was 566 cents. Finally, on 24 October 2018, a decision was taken by the board to commence with a Company Voluntary Arrangement process with the assistance of Grant Thornton.

\section{Dialogue}

The embodied perception of the individual implies a multilateral communication process between subjects in the world. Therefore, interaction between people is an important principle of economics. The notion of self-interest is embedded in a socio-ethical system that functions on the basis of the natural instinct that Smith referred to as sympathy. ${ }^{28,31,32}$ The implication is that an agency perspective that only highlights self-interest and individualism does not follow the foundations of classic economics with its very important social dimension. The social dimension is inclusive and geared toward not only the short-term self-interest of a business and principals but also the long-term sustainability of the business in society. This is crucially important for the FM because instead of the individual proceeding in isolation it is important that dialogue takes place with stakeholders. The importance of dialogue is critical because it highlights our presuppositions. In this process, difference and overlap are crucial for constructive dialogue. Difference highlights the presuppositions of the subjects and the possibility of creative problem-solving. Dialogue also emphasises the possible overlap that can be the basis for consensus. The difference and overlap together are essential to move beyond the limits of solipsism by revealing an alternative perspective that will make decision-making more inclusive and nuanced.

In their 2017 financial statements, FB determined the fair value of the investment in GBK by applying the DCF method. As mentioned, the key assumptions included the probability that GBK would reach the set targets and the appropriateness of the discount rate. At this stage, the discount rate was set at 9.33\%. Assumptions regarding the anticipated profit were 
based on historical performance adjusted for expected growth. In estimating the future profits, they applied a declining growth rate averaging $23 \%$ over a 5 -year period. The growth rate was estimated to be $1 \%$ per annum after the initial 5-year period. It was stated that a change of $1 \%$ in the future profits would result in a difference in value of $\mathrm{R} 9.1 \mathrm{~m}$. A change of $1 \%$ in the discount rate could result in a movement of $R 7.5 \mathrm{~m}$ in the value. The situation changed as was reported in the 2018 financial statements of FB. The recoverable amount dropped to R1.9 billion. The profits were now forecast over a 10-year period, with an initial growth rate of $0 \%$ growing to $3 \%$ in this period. The growth rate thereafter was estimated at $2.2 \%$ per annum. The discount rate used was $8 \%$.

According to $\mathrm{FB}$, the valuation was performed by valuation experts according to market data that was adjusted based on the experience of management and their knowledge of the market. However again, the valuation was based on the same assumptions as in 2017. The financial statements reflect that the discount rate used was determined based on market rates and adjusted for risk. This highlights the problem associated with calculations and qualitative aspects like experience in determining the value. Could dialogue with more stakeholders have contributed to a more reasonable assessment? This dialogue can also be extended to include valuations from various valuators that follow different strategies and philosophies to produce counter-arguments to the exorbitant valuation that was eventually accepted by the board.

\section{Accountability}

The fact that the presence of the subject in the world has an impact on the environment and other people reveals that accountability and, therefore, a responsible interpretative practice are paramount. The reason for this is that meaning creation is an inclusive activity that is based on the fact that interpretation is an engaged activity. This implies that every act of interpretation has to be performed in a transparent manner that follows the procedures and methods of the profession, which is also inclusive of all relevant stakeholders pertaining to a particular calculation. Accountability assumes that the embodied perception of the subject comes into play, and the biases of the subject require recognition and giving account of decisions to stakeholders. Practically, it requires transparency through reporting.

Accountability means that it is not only a culture of individualism and self-interest that should drive the accounting profession as is reflected in the different Codes of Ethics. Rather, the embedded nature of the profession in society must also be reflected in the way decisions are made that is not limited to the perspectives of agency theory but includes the well-being of others. Accountability is part of Smith's $\mathrm{s}^{34,35}$ understanding of economics as a socio-ethical system in which the impartial spectator is an important mechanism to determine responsible behaviour. The impartial spectator is a mental construction created by a subject of the engagement between people and events based on the experience to determine a response that will result in the approbation of others. ${ }^{36}$ In this process, the perceptions of others are paramount, and influence the subject's perceptions and actions. Behaviour that is offensive or harmful to others has a direct impact on the subject. The subject will in such a situation not receive approbation from others that may have direct consequences. ${ }^{28}$ Hence, the agency perspective that mainly considers the principal and possible conflict of interests with agents must be expanded to incorporate a holistic perspective that respects the interconnected nature of business as a social phenomenon, amongst others. Therefore, recognition of others beyond the parameters that agency theory and the individualism of stakeholder theory is required. ${ }^{37}$

This failure can be seen in the way FM decisions are sometimes informed by the calculation of discount rates and cash flow projections without transparency beyond what is required from management by agency theory. These are crucial processes that may have a negative impact on stakeholders. For example, if cash flows are estimated too conservatively, the implication will be that a company might be undervalued or that a project might seem to yield a negative NPV and may not be undertaken. If a project is rejected on the basis of this negative NPV, it has a direct impact on the value of the company and the wealth of the shareholders as the project could have added value to the company. However, the danger of being too optimistic may result in accepting a project that may not yield the value expected or could even destroy the value. Or, if the value of a company in which a company wishes to invest is overestimated, the company could pay too much for the equity of the other company. This will have impact on the company and shareholder value, job security of employees, loss of income to suppliers, the community and so on. For this reason, it is crucial that for the practice of determining value and ultimately making investment decisions, a more inclusive process is followed by sharing information with stakeholders so that a more realistic and sustainable decision can be made. In the end, this will create the buy-in of the stakeholders and positive sentiment towards a possible project that is imperative for its success and reaching the financial goal that informed the decision in the first place. If a community boycotts a company and does not support the business because of legacy issues or other reasons, this could be detrimental to the sustainability of the business.

In the case study, the investment decision to purchase GBK was based on uninformed and too optimistic estimates of potential cash flows and discount rates. The share price of FB dropped by $46 \%$, and the debt burden of the loss-making business resulted in the cancellation of dividends. The job security of GBK staff is compromised, as well as the other franchises owned by FB. These and other implications of the decision to invest in GBK highlight the failure of responsible decision-making and accountability to stakeholders because of the overvaluation of the cash flow estimates and possibly inaccurate discount rates. 


\section{Contextual awareness}

The contextual nature of interpretation accentuates the fact that embodied perception takes place in the world. This brings the physical and geographical space of interpretation and time into focus. The calculation and decision-making are always contextually based on a particular historical and physical situation. Context also plays an important role in classic economics for Smith's concept of sympathy. ${ }^{32}$ This had direct bearing on the situation and the circumstances surrounding an event in which the impartial spectator judged a situation and amended perception and action to attain approbation. Physical context is directly linked to the resources, scarcity and variables associated with space. History assumes that any decision must take legacy issues into consideration, and possible adjustments should be made. Therefore, the reference to context is generally ontological in terms of the reference to the awareness of the influence of circumstances that are historically embedded. In the context of this article, it denotes society, in general, in terms of the operations of a business and the larger macroeconomic influences. Furthermore, context is not neutral or value free, and socio-political and other aspects are important to consider. Context can, therefore, be viewed as a leap beyond stakeholder theory by scrutinising the power dynamics of the complex network of stakeholders.

The integrated report of FB of 2018 states that economic and socio-political factors that contributed to the loss of value included Brexit that resulted in a weaker economy and lower consumer confidence. For this reason, consumers became price sensitive, which posed a problem as GBK's products are seen as expensive. Furthermore, there was a decline of sales in malls and eat-in restaurants and an increase in online and delivery sales. An increase of competition in the premium burger sector where the number of restaurants has grown at a compound annual growth rate of $23 \%$ further had a negative impact on GBK's results. Sales declined by $6.8 \%$ for the 2018 financial year. Ironically, Damon Buss, an equity analyst at Electus Fund Managers, raised the question of why the Enthoven family would sell GBK if it had such a great potential.

Context played a crucial role in this decision. Brexit and the possibility of the UK losing its role as a financial hub of Europe, trade restrictions and other negative economic aspects directly influenced the growth of the British economy. According to Buss, the first sign the GBK acquisition was illconceived was the revelation that the Enthoven family were the sellers. 'Why would the owners of Nando's sell a business if it had such great potential?'. ${ }^{38}$ Context not only relates to Britain, it also reflects the South African context and the capital flight of companies (e.g. Woolworths and Brait) who overpaid for businesses to secure currency hedge opportunities in GBP, US\$ and others. Issues in South Africa which may have triggered a far more optimistic valuation of GBK include political instability, corruption, low economic growth and downgrades by Stanley and Poor. A more inclusive dialogue and greater drive to be accountable may have had a great impact on this business decision. It is clear from this study that contextual awareness broadened the qualitative assessment by not basing the valuation on similar companies in the same geographical location and economy; rather the comparison could have been more accurate if a country that experienced a financial shock or risk was chosen. This comparison could have provided a clearer risk profile.

\section{Conclusion}

In this article, the phenomenology of Merleau-Ponty was explored as the basis of an embodied interpretative process for FMs, which goes beyond agency theory. This interpretative process consists of three principles, namely, dialogue, accountability and context. The contribution of this philosophical perspective on financial management is that qualitative assumptions are used as a tool for critical and engaged decision-making with specific reference to valuations. However, these principles can also be used for decisionmaking by FMs, in general. Dialogue with stakeholders and a sense of accountability enable a FM to identify key stakeholders in investment decision-making in order to scrutinise the individual's presuppositions. This is important because aspects that may be crucial to decision-making could be revealed. The principle of context is a further aspect that should be evaluated and in the case of the purchase of GBK by FB exposed the possible danger of simplistic use of currency hedging as a reason for exorbitant valuations. Therefore, it is clear that dialogue, accountability and context are significant principles for responsible investment decision-making.

\section{Acknowledgements Competing interest}

The authors declare that they have no financial or personal relationships that may have inappropriately influenced them in writing this research article.

\section{Authors' contributions}

M.R. and S.v.R. contributed equally to this research article.

\section{Ethical considerations}

The EMS-REC of the North-West University reviewed the research and concluded that this is a no-risk study. NWU00665-20-A4.

\section{Funding information}

This research received no specific grant from any funding agency in the public, commercial or not-for-profit sectors.

\section{Data availability}

The authors confirm that the data supporting the findings of this study are available within the article.

\section{Disclaimer}

The views and opinions expressed in this research article are those of the authors and do not necessarily reflect the official policy or position of any affiliated agency of the authors. 


\section{References}

1. Van Rooyen S. Business theories. In: Rathbone M, editor. Understanding busines and ethics in the South African context. Pretoria: Van Schaik, 2020; p. 182-197.

2. Eisenhardt KM. Agency theory: An assessment and review. Acad Manag Rev 1989;14(1):57-74. https://doi.org/10.5465/amr.1989.4279003

3. Lander DM, Pinches GE. Challenges to the practical implementation of modeling and valuing real options. Q Rev Econ Finance. 1998:38(3):537-567. https://doi. and valuing real options. Q Rev Econ
$\mathrm{org} / 10.1016 / \mathrm{S} 1062-9769(99) 80089-1$

4. Xue W. The fallacies of corporate investment appraisal: A discussion of share price maximization. International conference on logistics engineering, management and computer science; 2015 July 29-31, Shenyang: Atlantis Press; 2015, p. 941-945.

5. Magni CA. Reasoning the 'net-present-value' way: Some biases and how to use psychology for falsifying decision models [homepage on the Internet]. 2005 [cited 2018 Nov 20]. Available from: https://ssrn.com/abstract=1673371

6. Magni CA Investment decisions, net present value and bounded rationality. Quan Finance. 2009;9(8):967-979. https://doi.org/10.1080/14697680902849338

7. PwC. Closing the value gap: Valuation methodology survey 2016/17 [homepage on the Internet]. 2017 [cited 2020 Nov 24]. Available from: https://www.pwc. co.za/en/assets/pdf/closing-the-value-gap-2016-2017.pdf

8. Correia C, Flynn D, Uliana E, Wormald M, Dillon J. Financial management. 9th ed. Cape Town: Juta; 2019.

9. Graham J, Harvey C. How do CFOs make capital budgeting and capital structure decisions? J Appl Corp Finance. 2002;15(1):8-22. https://doi. org/10.1111/j.1745-6622.2002.tb00337.x

10. Hornung $M$. Heuristic reasoning in the setting of hurdle rates and in the projection of cash flows in investment appraisal [PhD dissertation]. University of West England; 2017.

11. Bierman $\mathrm{H}$, Hass JE. Capital budgeting under uncertainty: A reformulation. J Finance. 1973;28(1):119-129. https://doi.org/10.1111/j.1540-6261.1973.tb01350.x

12. Hamada RS. Portfolio analysis, market equilibrium and corporation finance. $J$ Finance. 1969;24(1):13-31. https://doi.org/10.1111/j.1540-6261.1969.tb00339.x

13. Mossin J. Security pricing and investment criteria in competitive markets. Am Econ Rev. 1969;59:749-756.

14. Rubinstein M. .A mean-variance synthesis of corporate financial theory. J Finance. 1973;28(1):167-182. https://doi.org/10.1111/j.1540-6261.1973.tb01356.x

15. Tuttle DL, Litzenberger RH. Leverage, diversification and capital market effects on a risk-adjusted capital budgeting framework. J Finance. 1968;23(3):427-443. https://doi.org/10.1111/j.1540-6261.1968.tb00818.x

16. McDonald RL. Real options and rules of thumb in capital budgeting. In Brennan MJ, Trigeorgis L, editors. Project flexibility, agency and competition: New developments in the theory and application of real options. New York, NY: Oxford University Press, 2000; p. 13-33.

17. Summers LH. Investment incentives and the discounting of depreciation allowances. In Feldstein M, editor. The effects of taxation on capital accumulation. Chicago, IL: University of Chicago Press, 1987, p. 295-304.

18. Einhorn HJ, Hogarth RM. Behavioral decision theory: Processes of judgment and choice. Annu Rev Psychol. 1981;32:53-88. https://doi.org/10.1146/annurev. ps.32.020181.000413

19. Luft J, Shields MD. Psychology models of management accounting. Found Trends Account. 2010;4(3-4):199-345. https://doi.org/10.1561/1400000015
20. Daily CM, Dalton DR, Canella AA. Corporate governance: Decades of dialogue and data. Acad Manag Rev. 2003;28(3):371-382. https://doi.org/10.5465/ amr.2003.10196703

21. Adler RW. Strategic investment decision appraisal techniques: The old and the new. Bus Horiz. 2000;43(6):15-22. https://doi.org/10.1016/S00076813(00)80017-8

22. Bampton R, Cowton CJ. Pioneering in ethics teaching: The case of management accounting in universities in the British Isles. Teach Bus Ethics. 2002;6(3):279-295. https://doi.org/10.1023/A:1016143911361

23. Husserl E. Logical investigations. Findlay JN, translator. London: Routledge; [1900] 1973.

24. Kant I. Critique of pure reason. Smith NK, translator. London: Macmillan; 1781.

25. Heidegger M. Being and time. Macquarrie J, Robinson E, translator. London: SCM Press; 1960

26. Gadamer H-G. Truth and method. 2nd rev. ed. 1st English ed. 1975, Glen-Doepel W, translator, Cumming J, Barden G, editors. Weinsheimer J, Marshall DG, rev. translators. New York, NY: Crossroad; [1960] 1989.

27. Merleau-Ponty M. Phenomenology of perception. Smith C, translator. London: Routledge; 1962.

28. Rathbone M. Adam Smith, the impartial spectator and embodiment: Towards an economics of accountability and dialogue. Religions. 2018;9(4):118. https://doi. org/10.3390/rel9040118

29. Merleau-Ponty M. The primacy of perception and other essays on phenomenological psychology, the philosophy of art, history and politics. Edie JM, editor. Evaston, IL: Northwestern University Press; 1964.

30. Merleau-Ponty M. The visible and the invisible. Lefort C, editor. Lingis A, translator Evaston, IL: Northwestern University Press; 1968.

31. Rathbone M. Love, money and madness: Money in the economic philosophies of Adam Smith and Jean-Jacques Rousseau. S Afr J Philos. 2015;34(3):379-389. https://doi.org/10.1080/02580136.2015.1087614

32. Rathbone M. Desire, self-love and sympathy: The irony of discovering Adam Smith in post-capitalism economics. S Afr J Philos. 2019;38(1):96-107. https:// doi.org/10.1080/02580136.2019.1581426

33. Adams S. South Africa's Famous Brands gobbles up Gourmet Burger Kitchen UK. The South African [serial online]. 2016 [cited 2018 Nov 20]. Available from: https://www.thesouthafrican.com/lifestyle/south-africans-abroad/south-africas famous-brands-gobbles-gourmet-burger-kitchen-uk/

34. Smith A. The theory of moral sentiments. Cambridge: Cambridge University Press; [1759] 2004.

35. Smith A. An inquiry into the nature and causes of the wealth of nations. Edited with introduction, notes, marginal summary and an enlarged index by Cannon, $\mathrm{E}$. London: Methuen \& Co. Ltd.; [1776] 1950

36. Rathbone M. Understanding business and ethics in the South African context. Pretoria: Van Schaik; 2020.

37. Rathbone M. Unemployment and the gift in the South African context: Towards an economics of recognition and humility. Koers. 2017:82(1):1-11. https://doi. org/10.19108/KOERS.82.1.2324

38. Hedley N. How Famous Brands' UK burger business went from bad to worse. Business Day [serial online]. 2018 [cited 2018 Nov 20]. Available from: https:// www.businesslive.co.za/bd/companies/retail-and-consumer/2018-10-16-howfamous-brands-uk-burger-business-went-from-bad-to-worse/ 